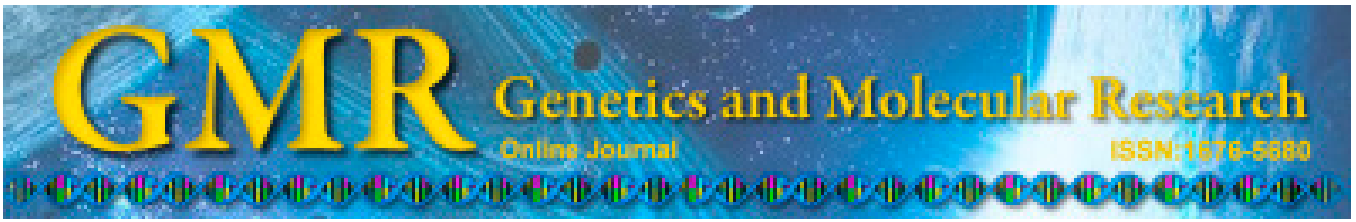

\title{
Type II deiodinase polymorphisms and serum thyroid hormone levels in patients with mild cognitive impairment
}

\author{
M. Luo, X.H. Zhou, T. Zou, K. Keyim and L.M. Dong \\ Department of Cadre Ward, Department of Geriatrics, \\ First Affiliated Hospital of Xinjiang Medical University, Urumqi, China \\ Corresponding author: X.H. Zhou \\ E-mail: zhouxiaohui858@sina.com
}

Genet. Mol. Res. 14 (2): 5407-5416 (2015)

Received May 27, 2014

Accepted October 17, 2014

Published May 22, 2015

DOI http://dx.doi.org/10.4238/2015.May.22.10

\begin{abstract}
We investigated type II deiodinase $\left(\mathrm{DIO}_{2}\right)$ polymorphisms and serum thyroid hormone levels in subjects with mild cognitive impairment (MCI) in a Uygur population. We studied the $\mathrm{DIO}_{2}$ Thr92Ala (rs225014) and ORFa-Gly3Asp (rs12885300) polymorphisms of 129 unrelated MCI cases and 131 matched controls. All subjects were genotyped using SNaPshot SNP genotyping assays. Serum thyroid hormone levels were measured by radioimmunoassay. Levels of serum triiodothyronine and thyroxine in the MCI group were significantly lower than those in the control group. Genotype and allele frequencies in the $\mathrm{DIO}_{2}$ gene between the MCI and control groups were not significantly different. There was no association in genotype and allele frequencies of Thr92Ala between genders in both groups. ORFa-Gly3Asp genotype and allele frequencies were significantly different in patients and controls by gender. The Asp allele was less frequent among male MCI patients compared to controls (odds ratio $=0.471,95 \%$ confidence interval $=$ 0.261-0.848). However, female Asp carriers were more frequent among MCI patients than among controls (odds ratio $=2.842,95 \%$ confidence interval $=1.326-6.09$ ). Serum levels of triiodothyronine and thyroxine
\end{abstract}


were lower in individuals of the Ala/Ala genotype than in those with the Thr/Thr or Thr/Ala genotype. Serum levels of triiodothyronine were lower in male Gly/Gly carriers than in Gly/Asp or Asp/Asp carriers. Decreased serum levels of triiodothyronine and thyroxine may influence the incidence of $\mathrm{MCI}$ in the Uygur population. $\mathrm{DIO}_{2}$ gene polymorphisms may play a role in the incidence of MCI in male patients.

Key words: Gene; Mild cognitive impairment; Polymorphism; Uygur; Thyroid hormone; Type 2 deiodinase

\section{INTRODUCTION}

Mild cognitive impairment (MCI) is an intermediate state between normal ageing and dementia, defined by the impairment of memory and other cognitive domains that are not sufficiently severe to be diagnosed as Alzheimer's disease (AD). We previously found that in addition to recognized independent risk factors for MCI such as hypertension, sugar metabolism disorders, and hyperlipidemia (Zhou et al., 2012), low triiodothyronine $\left(\mathrm{T}_{3}\right)$ level may be an independent risk factor for MCI. Previous studies have found that $\mathrm{T}_{3}$ may promote the formation of central nervous system stem cells and glial cell differentiation and is closely related to cognitive function (Lazarus, 2012). Deiodinase is a key enzyme of thyroid hormone (TH) metabolism; in particular, type 2 deiodinase $\left(\mathrm{DIO}_{2}\right)$ is a key enzyme that regulates $\mathrm{T}_{3}$ in brain tissues.

We hypothesized that genetic variations in the $\mathrm{DIO}_{2}$ gene alter the bioactivity of THs associated with MCI. Thus, we performed a case-control study of a Uygur population of Hetian in Xinjiang based on previous epidemiological survey research.

\section{MATERIAL AND METHODS}

\section{Subjects}

Our sample was collected according to a cluster sampling design and geographical distribution. The study was carried out between August and October 2010. Using a random number table, 3346 Uygur participants were enrolled, aged 55 years or older, in Hetian. To evaluate MCI, the diagnostic criteria proposed by the Diagnostic and Statistical Manual of Mental Disorders 4th edition was used based on data from epidemiological surveys. Exclusion criteria included history of mental illness or mental retardation or suffering from severe heart or lung or kidney dysfunction, severe endocrine disease, severe infectious diseases, and toxic encephalopathy. Subjects with brain dysfunction such as stroke, Parkinson's disease, brain tumors, depression, a history of head trauma, or a history of psychotropic drug use, alcohol, or drug addiction in the past 6 months were also excluded. Those with primary thyroid disease and taking thyroid medication and iodine within 2 weeks were excluded. A total of 324 subjects diagnosed with MCI were recruited, including 156 male and 168 female Uygur cases. A total of 129 patients with MCI $[74$ males and 55 females with a mean \pm standard deviation (SD) age of $64.3 \pm 6.42$ years] and 131 psychiatrically healthy control subjects (75 males and 56 females with a mean age of $64.4 \pm 6.45$ years) were recruited for this case-control study. All subjects were unrelated native Chinese Uygur people. Control subjects matched by distribution, education, past history, and illness were included. All subjects participated in this study 
voluntarily. Written informed consent was obtained from all subjects following a complete description of the study. The institutional Ethics Committees approved this study.

\section{Methods}

\section{Blood sample measurement}

We collected $5 \mathrm{~mL}$ fasting blood samples from participants at baseline between 8:30 a.m. and 10:00 a.m. Plasma and serum were separated from blood cells within $1 \mathrm{~h}$ of collection and stored at $-80^{\circ} \mathrm{C}$ until assayed. Blood samples for blood lipids, blood glucose, and homocysteine concentration were collected in empty tubes and analyzed by a biochemical laboratory (Beckman, Brea, CA, USA). Serum $\mathrm{T}_{3}$, thyroxine $\left(\mathrm{T}_{4}\right)$, and thyroid stimulating hormone were measured using an $\left[{ }^{125} \mathrm{I}\right]$ iodine triiodothyronine, $\left[{ }^{125} \mathrm{I}\right]$ iodine thyroxine, and human thyrotropin radioimmunoassay kit from the North Biology Institute of Beijing.

\section{Genotyping}

Genomic DNA was isolated from ethylenediaminetetraacetic acid blood samples using the Genomic DNA Mini Kit (TIANGEN, Beijing, China). The primers for Thr92Ala and ORFaGly3Asp were designed using the Primer3 software (http://frodo.wi.mit.edu/). The primer sequences for analyzing DNA samples are listed in Table 1. Oligonucleotides were synthesized by Sangon Biotech Co., Ltd. (Shanghai, China). Multiplex polymerase chain reaction amplification included $(20 \mu \mathrm{L})$ : $1 \mathrm{X}$ GC Buffer I, $3.0 \mathrm{mM} \mathrm{Mg}{ }^{2+}, 0.3 \mathrm{mM}$ dNTPs, 1 U HotStarTaq polymerase (Qiagen, Hilden, Germany), $1 \mu \mathrm{L}$ DNA, and $2 \mu \mathrm{L}$ multiplex amplification primers. The cycling for amplification consisted of denaturation at $95^{\circ} \mathrm{C}$ for $2 \mathrm{~min}, 11$ cycles of denaturation at $94^{\circ} \mathrm{C}$ for $20 \mathrm{~s}$, annealing at $65^{\circ} \mathrm{C}$, increasing by $0.5^{\circ} \mathrm{C} /$ cycle for $40 \mathrm{~s}$, and extension at $72^{\circ} \mathrm{C}$ for $90 \mathrm{~s}$, followed by 24 cycles of denaturation at $94^{\circ} \mathrm{C}$ for $20 \mathrm{~s}$, annealing at $59^{\circ} \mathrm{C}$ for $30 \mathrm{~s}$, and extension at $72^{\circ} \mathrm{C}$ for $90 \mathrm{~s}$, and final extension at $72^{\circ} \mathrm{C}$ for $2 \mathrm{~min}$. According to the ABI PRISM SNaPshot Multiplex Kit Protocol, the amplified products were pooled for each sample and purified by digestion with $2 \mathrm{U}$ exonuclease I and $5 \mathrm{U}$ shrimp alkaline phosphatase at $37^{\circ} \mathrm{C}$ for $1 \mathrm{~h}$ to remove unutilized primers and dNTPs. The enzymes were heat-inactivated by incubation at $75^{\circ} \mathrm{C}$ for $15 \mathrm{~min}$.

Table 1. Oligonucleotides used for cDNA polymerase chain reaction.

\begin{tabular}{llc}
\hline Primer & Sequence (5'-3') & Fragment (bp) \\
\hline rs225014 (Thr92Ala) & F: CTGGCTCGTGAAAGGAGGTCAA & 173 \\
rs225014 (Thr92Ala) & R: CCAATTCCAGTGTGGTGCATGT & 170 \\
rs12885300 (Gly3Asp) & F: GGCGTACTCGTCCCTAATCCAGT & 170 \\
rs12885300 (Gly3Asp) & R: TGGCAATTCAAGAAAGAAACAGGCTAC & \\
\hline
\end{tabular}

Genotyping was performed using the SNaPshot Multiplex kit (Applied Biosystems, Foster City, CA, USA). Briefly, approximately $2 \mu \mathrm{L}$ purified amplicon was added to $5 \mu \mathrm{L}$ SNaPshot Ready Reaction Mix and $1 \mu \mathrm{L}$ of each SNaPshot oligonucleotide primer (Table 2). The reactions were carried out for 28 cycles at $96^{\circ} \mathrm{C}$ for $10 \mathrm{~s}, 52^{\circ} \mathrm{C}$ for $5 \mathrm{~s}$, and $60^{\circ} \mathrm{C}$ for $30 \mathrm{~s}$ in a polymerase chain reaction Verity 96-well instrument (Applied Biosystems) and digested with shrimp alkaline phosphatase to dephosphorylate unincorporated fluorescent ddNTPs. The $\mathrm{SNaPshot}$ reaction products were analyzed in 3130xl genetic analyzer (Applied Biosystems) 
by mixing $0.5 \mu \mathrm{L}$ SNaPshot product, and $0.5 \mu \mathrm{L}$ GS120 Liz Size Standard (Applied Biosystems) and $9 \mu \mathrm{L}$ Hi-Di Formamide (Applied Biosystems) for each sample and denaturing the injection mix at $95^{\circ} \mathrm{C}$ for $5 \mathrm{~min}$. Subsequent automated genotype analysis was performed using GeneMapper 4.1 (Applied Biosystems).

\begin{tabular}{|c|c|}
\hline Primer & Sequence $\left(5^{\prime}-3^{\prime}\right)$ \\
\hline $\begin{array}{l}\mathrm{rs} 225014 \mathrm{SF} \\
\mathrm{rs} 12885300 \mathrm{SR}\end{array}$ & $\begin{array}{l}\text { TTTTTCCACTGTTGTCACCTCCTTCTG } \\
\text { TTTCGTTAAAGAGCATAGAGACAATGAAAG }\end{array}$ \\
\hline
\end{tabular}

\section{Statistical analyses}

All continuous variables are reported as means $\pm \mathrm{SD}$. Differences in continuous variables between MCI patients and control subjects were analyzed using the 2-tailed paired Student $t$-test and one-way analysis of variance. Chi-squared tests were used to determine whether samples were in Hardy-Weinberg equilibrium. Differences in the distributions of genotypes and alleles between MCI patients and control subjects were analyzed using the Fisher exact test. Risk factors for MCI, based on odds ratios (OR) and 95\% confidence intervals (CI), were analyzed. $\mathrm{P}<0.05$ was considered to indicate statistical significance. Data were analyzed using SPSS V 17.0 (SPSS, Inc., Chicago, IL, USA).

\section{RESULTS}

\section{Clinical characteristics of study participants}

Table 3 shows the clinical characteristics of the study participants. For total subjects, the following factors were significantly higher in the MCI patients compared to control subjects: systolic blood pressure, triglycerides, and low-density lipoprotein-cholesterol. The following factors showed no significant differences between MCI patients and control subjects: age, body mass index, diastolic blood pressure, glucose, total cholesterol, and high-density lipoprotein-cholesterol. MCI patients showed significantly lower $\mathrm{T}_{3}$ and $\mathrm{T}_{4}$ levels compared to control subjects $(\mathrm{P}<0.05)$.

\begin{tabular}{|c|c|c|c|c|}
\hline & MCI patients & Control subjects & $t$ & $P$ value \\
\hline Number of subjects $(\mathrm{N})$ & 129 & 131 & & \\
\hline Age (years) & $64.32 \pm 6.42$ & $64.41 \pm 6.46$ & 0.118 & 0.906 \\
\hline BMI $\left(\mathrm{kg} / \mathrm{m}^{2}\right)$ & $24.67 \pm 4.23$ & $23.96 \pm 4.10$ & 1.377 & 0.170 \\
\hline Systolic BP (mmHg) & $140.72 \pm 24.07$ & $133.49 \pm 24.21$ & 2.416 & $0.016 *$ \\
\hline Diastolic BP (mmHg) & $80.69 \pm 12.90$ & $78.07 \pm 13.10$ & 1.625 & 0.105 \\
\hline Fasting plasma glucose $(\mathrm{mM})$ & $6.03 \pm 2.96$ & $5.47 \pm 1.81$ & 1.829 & 0.069 \\
\hline Triglycerides (mM) & $2.99 \pm 1.39$ & $2.04 \pm 1.26$ & 5.832 & $0.000^{*}$ \\
\hline Total cholesterol (mM) & $4.70 \pm 0.87$ & $4.50 \pm 1.02$ & 1.751 & 0.081 \\
\hline HDL cholesterol (mM) & $1.06 \pm 0.26$ & $1.10 \pm 0.45$ & 0.878 & 0.381 \\
\hline LDL cholesterol (mM) & $2.77 \pm 0.73$ & $2.40 \pm 0.61$ & 4.355 & $0.000^{*}$ \\
\hline $\mathrm{T}_{3}(\mathrm{ng} / \mathrm{mL})$ & $1.32 \pm 0.40$ & $1.56 \pm 0.74$ & 3.223 & $0.001 *$ \\
\hline $\mathrm{T}_{4}^{3}(\mathrm{ng} / \mathrm{mL})$ & $84.98 \pm 17.91$ & $93.50 \pm 23.21$ & 3.318 & $0.001 *$ \\
\hline TSH (IU/mL) & $6.08 \pm 2.63$ & $5.68 \pm 2.13$ & 1.369 & 0.172 \\
\hline
\end{tabular}




\section{SNaPshot method}

The representative data are shown in Figure 1. For the rs12885300 polymorphisms, Gly/Gly genotype produced a blue peak, Asp/Asp genotype produced a green peak, and Gly/ Asp genotype produced a blue and green peak. For the rs 225014 polymorphisms, the Thr/Thr genotype produced a red peak, the Ala/Ala genotype produced a black peak, and the Thr/Ala genotype produced red and black peaks.

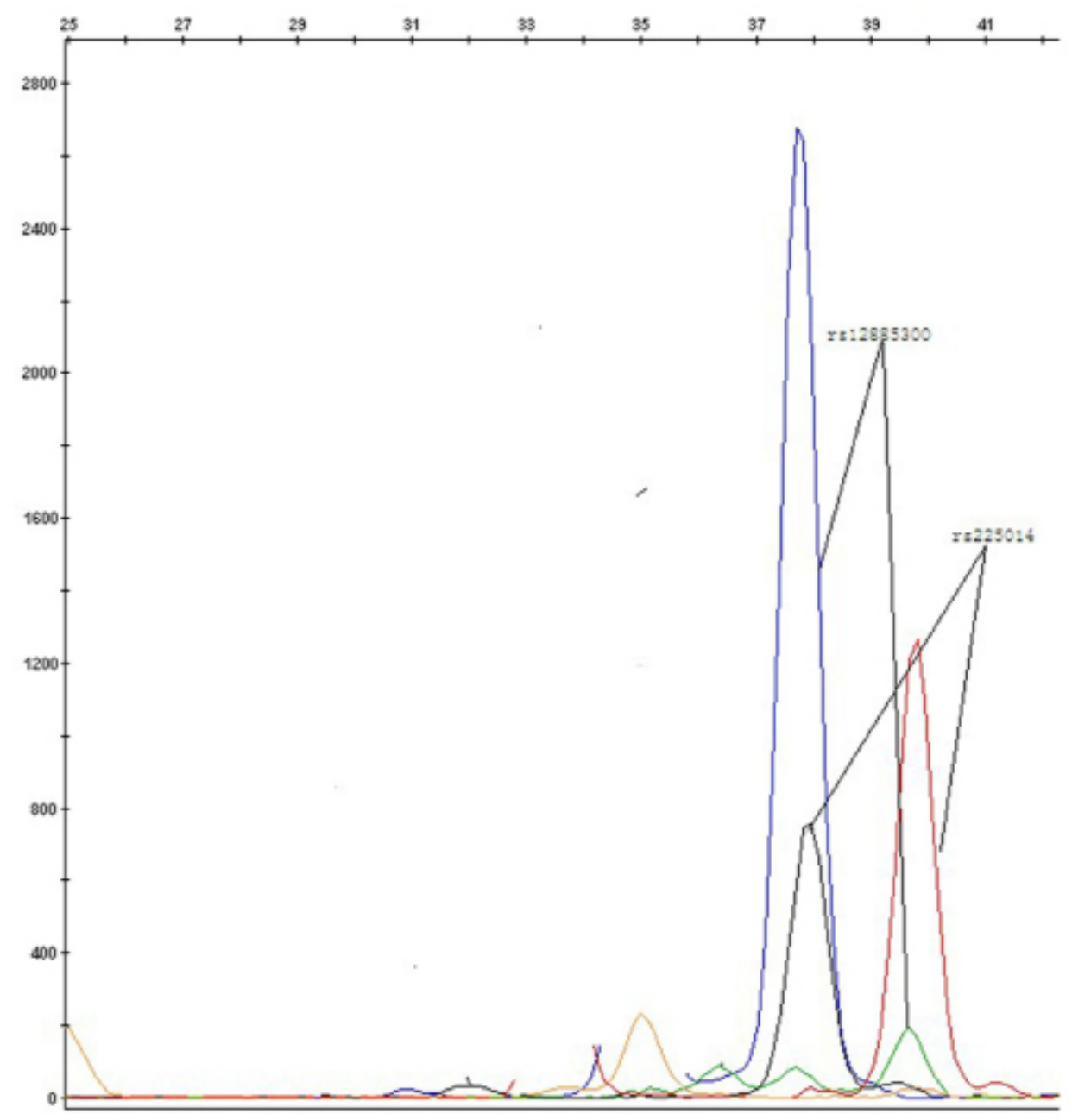

Figure 1. Blue = ddGTP; green $=$ ddATP; red $=$ ddTTP; black $=$ ddCTP .

\section{Genotype and allele frequencies of the $\mathrm{DIO}_{2}$ gene}

The distributions of genotypes of rs225014 and rs12885300 were both in HardyWeinberg equilibrium in the MCI and control groups. There was no association between geno- 
type and allele frequencies in the $\mathrm{DIO}_{2}$ gene common mutation and $\mathrm{MCI}$ group compared to control subjects $(\mathrm{P}>0.05$, Table 4$)$.

\begin{tabular}{|c|c|c|c|c|c|}
\hline Locus & Type & MCI patients & Control subjects & $\chi^{2}$ & P value \\
\hline \multirow[t]{5}{*}{ rs225014 } & Thr/Thr & $40(31)$ & $43(32.8)$ & 0.275 & 0.871 \\
\hline & $\mathrm{Thr} / \mathrm{Ala}$ & $57(44.2)$ & $59(45)$ & & \\
\hline & $\mathrm{Ala} / \mathrm{Ala}$ & $32(24.8)$ & $29(22.2)$ & & \\
\hline & Thr & $137(53.1)$ & $145(55.3)$ & 0.263 & 0.608 \\
\hline & Ala & $121(46.9)$ & $117(44.7)$ & & \\
\hline \multirow{5}{*}{ rs12885300 } & Gly/Gly & 88 (68.2) & $83(63.4)$ & 3.625 & 0.163 \\
\hline & Gly/Asp & $35(27.1)$ & $46(35.1)$ & & \\
\hline & Asp/Asp & $6(4.6)$ & $2(1.5)$ & & \\
\hline & Gly & $211(81.8)$ & $212(0.72)$ & 0.064 & 0.8 \\
\hline & Asp & $47(18.2)$ & $50(0.28)$ & & \\
\hline
\end{tabular}

We observed no association in genotype frequencies and allele frequencies of rs 225014 and gender in the MCI group or control group $(\mathrm{P}>0.05)$. However, the Ala allele frequency for males in the MCI group was higher than that in the control group, although no significant difference was observed (48.6 vs 38.7\%, $\mathrm{P}=0.08)$. The genotype and allele frequencies of rs12885300 were significantly different between patients with MCI and controls according to gender $(\mathrm{P}>0.05)$. Male carriers of the Gly/Gly and Asp/Asp genotypes and the Gly allele were more common among MCI patients than among controls $(\mathrm{P}<0.05)$, but the Gly/Asp genotype and Asp allele were less frequently observed in MCI patients compared with controls (OR for male carriers of the Asp allele for $\mathrm{MCI}=0.471,95 \% \mathrm{CI}=0.261-0.848, \mathrm{P}=0.011$ ). However, female carriers of the Asp allele were more frequent among MCI patients than among controls $(\mathrm{P}<0.05)$. The OR for female carriers of the Asp allele for MCI was $2.842(95 \% \mathrm{CI}=1.326-$ $6.09, \mathrm{P}=0.006$; Table 5).

Table 5. Genotype and allele frequencies for $\mathrm{DIO}_{2}$ according to gender $(\mathrm{N}, \%)$.

\begin{tabular}{|c|c|c|c|c|c|c|}
\hline Locus & Gender & Type & MCI patients & Control subjects & $\chi^{2}$ & P value \\
\hline \multirow[t]{10}{*}{ rs225014 } & \multirow[t]{5}{*}{ Male } & $\mathrm{Thr} / \mathrm{Thr}$ & $22(29.7)$ & $30(40)$ & \multirow[t]{3}{*}{2.71} & \multirow[t]{3}{*}{0.258} \\
\hline & & Thr/Ala & $32(43.2)$ & $32(42.7)$ & & \\
\hline & & $\mathrm{ALa} / \mathrm{Ala}$ & $20(27)$ & $13(17.3)$ & & \\
\hline & & Thr & $76(51.4)$ & $92(61.3)$ & \multirow[t]{2}{*}{3.02} & \multirow{2}{*}{0.08} \\
\hline & & Ala & $72(48.6)$ & $58(38.7)$ & & \\
\hline & \multirow[t]{5}{*}{ Female } & $\mathrm{Thr} / \mathrm{Thr}$ & $18(32.7)$ & $13(23.2)$ & \multirow[t]{3}{*}{1.446} & \multirow[t]{3}{*}{0.485} \\
\hline & & Thr/Ala & $25(45.5)$ & $27(48.2)$ & & \\
\hline & & $\mathrm{Ala} / \mathrm{Ala}$ & $12(21.8)$ & $16(28.6)$ & & \\
\hline & & Thr & $61(55.5)$ & $53(47.3)$ & \multirow[t]{2}{*}{0.72} & \multirow[t]{2}{*}{0.225} \\
\hline & & Ala & $49(44.5)$ & $59(52.7)$ & & \\
\hline \multirow[t]{10}{*}{ rs 12885300} & \multirow[t]{5}{*}{ Male } & Gly/Gly & $56(76)$ & $37(48)$ & \multirow[t]{3}{*}{13.85} & \multirow[t]{3}{*}{0} \\
\hline & & Gly/Asp & $15(20)$ & 37 (49) & & \\
\hline & & Asp/Asp & $3(4)$ & $1(3)$ & & \\
\hline & & Gly & $127(86)$ & $111(74)$ & \multirow[t]{2}{*}{7.81} & \multirow[t]{2}{*}{0.005} \\
\hline & & Asp & $21(14)$ & $39(26)$ & & \\
\hline & \multirow[t]{5}{*}{ Female } & Gly/Gly & $88(68.2)$ & $83(63.4)$ & \multirow[t]{3}{*}{10.01} & \multirow[t]{3}{*}{0.007} \\
\hline & & Gly/Asp & $35(27.1)$ & $46(35.1)$ & & \\
\hline & & Asp/Asp & $6(4.6)$ & $2(1.5)$ & & \\
\hline & & Gly & $211(81.8)$ & $212(0.72)$ & \multirow[t]{2}{*}{10.17} & \multirow[t]{2}{*}{0.001} \\
\hline & & Asp & $47(18.2)$ & $50(0.28)$ & & \\
\hline
\end{tabular}




\section{Relationship between TH level and SNP in $\mathrm{DIO}_{2}$}

The serum levels of $\mathrm{T}_{3}$ and $\mathrm{T}_{4}$ in subjects with the Ala/Ala genotype were lower than those in subjects with the Thr/Thr or Thr/Ala genotype (between groups, $\mathrm{P}<0.05$ ). Serum levels of $\mathrm{T}_{3}, \mathrm{~T}_{4}$, and thyroid stimulating hormone in subjects with different genotypes of ORFaGly3Asp were not significant $\left(\mathrm{P}>0.05\right.$; Table 6 ). Serum levels of $\mathrm{T}_{3}$ in male Gly/Gly carriers were lower those in Gly/Asp or Asp/Asp carriers of different genders $(\mathrm{P}<0.05)$. The serum levels of TH in female Gly/Gly carriers did not differ from those in Gly/Asp or Asp/Asp carriers $(\mathrm{P}>0.05$; Table 7$)$.

Table 6. Relationship between TH level and $\mathrm{DIO}_{2} \mathrm{SNP}$.
\begin{tabular}{lcccccc}
\hline $\mathrm{DIO}_{2}$ gene locus & & $\mathrm{N}$ & Frequency $(\%)$ & $\mathrm{T}_{3}(\mathrm{ng} / \mathrm{mL})$ & $\mathrm{T}_{4}(\mathrm{ng} / \mathrm{mL})$ & $\mathrm{TSH}(\mathrm{IU} / \mathrm{mL})$ \\
\hline $\mathrm{rs} 225014$ & $\mathrm{Thr} / \mathrm{Thr}$ & 83 & 31.9 & $1.59 \pm 0.65$ & $91.78 \pm 20.12$ & $5.78 \pm 1.98$ \\
& $\mathrm{Ala} / \mathrm{Thr}$ & 116 & 44.6 & $1.51 \pm 0.60$ & $90.85 \pm 22.26$ & $6.14 \pm 2.85$ \\
$\mathrm{Ala} / \mathrm{Ala}$ & 61 & 23.5 & $1.12 \pm 0.42$ & $82.86 \pm 19.30$ & $5.51 \pm 1.91$ \\
$\mathrm{rs} 12885300$ & $\mathrm{Gly} / \mathrm{Gly}$ & 171 & 65.8 & $1.41 \pm 0.56$ & $90.29 \pm 20.50$ & $6.06 \pm 2.64$ \\
& $\mathrm{Gly} / \mathrm{Asp}$ & 81 & 31.2 & $1.49 \pm 0.70$ & $87.93 \pm 22.84$ & $5.46 \pm 1.74$ \\
& Asp/Asp & 8 & 3 & $1.44 \pm 0.47$ & $81.30 \pm 16.44$ & $6.23 \pm 2.45$ \\
\hline
\end{tabular}

$\mathrm{T}_{3}=$ triiodothyronine; $\mathrm{T}_{4}=$ thyroxine; $\mathrm{TSH}=$ thyroid stimulating hormone. Levels of $\mathrm{T}_{3}$ compared with $\mathrm{Thr} / \mathrm{Thr}$, Thr/Ala, and Ala/Ala carriers, $\mathrm{F}=12.862, \mathrm{P}=0.000$; levels of $\mathrm{T}_{4}$ between groups, $\mathrm{F}=3.794, \mathrm{P}=0.024$; the levels of TSH between groups, $\mathrm{F}=1.469, \mathrm{P}=0.232$; levels of $\mathrm{T}_{3}$ compared with 3 genotypes in rs $12885300, \mathrm{~F}=0.441$, $\mathrm{P}=0.644$; levels of $\mathrm{T}_{4}$ between groups, $\mathrm{F}=0.930, \mathrm{P}=0.396$, levels of $\mathrm{TSH}$ between groups, $\mathrm{F}=1.849, \mathrm{P}=0.16$.

Table 7. Thyroid hormone level and rs12885300 according to gender.

\begin{tabular}{lcccccc}
\hline rs12885300 & & $\mathrm{N}$ & Frequency $(\%)$ & $\mathrm{T}_{3}(\mathrm{ng} / \mathrm{mL})$ & $\mathrm{T}_{4}(\mathrm{ng} / \mathrm{mL})$ & $\mathrm{TSH}(\mathrm{IU} / \mathrm{mL})$ \\
\hline Male & Gly/Gly & 92 & 61.7 & $1.35 \pm 0.51^{*}$ & $87.16 \pm 21.62$ & $6.15 \pm 2.74$ \\
& Gly/Asp+Asp/Asp & 57 & 38.3 & $1.60 \pm 0.74$ & $89.76 \pm 22.01$ & $5.59 \pm 1.71$ \\
Female & Gly/Gly & 79 & 71.2 & $1.31 \pm 0.56$ & $90.72 \pm 19.05$ & $5.99 \pm 2.56$ \\
& Gly/Asp+Asp/Asp & 32 & 28.8 & $1.40 \pm 0.45$ & $85.21 \pm 18.47$ & $5.41 \pm 2.02$ \\
\hline
\end{tabular}

$\mathrm{T}_{3}=$ triiodothyronine; $\mathrm{T}_{4}=$ thyroxine; $\mathrm{TSH}=$ thyroid stimulating hormone. Levels of $\mathrm{T}_{3}$ compared with male Gly/ Gly carriers and Gly/Asp + Asp/Asp carriers, $t=-2.502, \mathrm{P}=0.013$, levels of $\mathrm{T}_{4}$ compared with Gly/Asp + Asp/Asp carriers, $t=-0.707, \mathrm{P}=0.480$, levels of TSH compared with Gly/Asp+Asp/Asp carriers, $t=1.398, \mathrm{P}=0.164$; levels of $\mathrm{T}_{3}$ compared with female Gly/Gly carriers and Gly/Asp+Asp/Asp carriers, $t=-0.718, \mathrm{P}=0.475$, levels of $\mathrm{T}_{4}$ compared with Gly/Asp+Asp/Asp carriers, $t=1.396, \mathrm{P}=0.166$, levels of TSH compared with Gly/Asp+Asp/Asp carriers, $t=1.157, \mathrm{P}=0.250 . * \mathrm{P}<0.05$.

\section{DISCUSSION}

Observational evidence from animal and human studies showed that TH may play an important role in the development and function of the central nervous system. Patients with hypothyroidism may suffer decreased cerebral blood flow, cerebral hypoxia, unresponsiveness, poor memory, comprehension decline, and dementia or other symptoms. Cognitive deficits resulting from dysfunction in thyroid function may promote the occurrence of AD. In addition, increasing evidence supports a strong interrelationship between TH and the cholinergic system. Specifically, there is extensive inter-reliance between TH and acetylcholine, nerve growth factor, and hippocampal function (Mafrica and Fodale, 2008). TH plays a primary role in mnemonic processes by regulating insulin-like signaling and potentially modulating hip- 
pocampal cognitive processes (Jahagirdar and McNay, 2012). Hypothyroidism also increased the expression of the amyloid- $\beta$ protein precursor in animal experiments, which plays a key role in the pathogenesis of AD (O'Barr et al., 2006).

Additional data suggested that low TH is a risk factor for cognitive decline. Stern et al. (2004) found that higher $\mathrm{T}_{4}$ levels within the normal range were associated with increased future cognitive function. Moreover, women without dementia with the lowest $\mathrm{T}_{4}$ levels exhibited a higher risk for future cognitive decline. TH has a positive relationship with overall cognitive function in healthy, euthyroid older men (Prinz et al., 1999). Wang et al. (2011) also confirmed that $\mathrm{AD}$ and $\mathrm{MCI}$ patients show lower $\mathrm{T}_{3}$ levels, and emphasized the relationship between lower $\mathrm{T}_{3}$ and the development of MCI or AD. Bai al. (2011) examined features of cognitive function impairment in elderly patients with subclinical hypothyroidism and found that the main cognitive impairment in elderly subclinical hypothyroidism was memory disorder. However, there was no difference in attention, executive function, visuospatial, and word abstract ability. However, a study by Quinlan et al. (2010) suggested that among those with $\mathrm{MCI}, \mathrm{T}_{3}$ levels were inversely associated with cognitive performance across all domains. After stratifying MCI cases according to $\mathrm{T}_{3}$ levels, those with relatively high $\mathrm{T}_{3}$ levels showed impairment in memory as well as in visuospatial and executive functions. Those with $\mathrm{T}_{3}$ levels at or below the lower boundary of the normal range performed comparably to healthy controls. Thus, individuals with $\mathrm{T}_{3}$ levels in the high normal range may suffer increased cognitive decline. Our control subjects were matched with cases for age, gender, education, hypertension, diabetes, and other medical history. We showed that $\mathrm{T}_{3}$ and $\mathrm{T}_{4}$ levels in MCI patients were still lower than that in the control group. Thus, TH level is one of the main factors affecting cognitive function. This result is consistent with those of Stern et al. (2004) and Wang et al. (2011), but not with those of Quinlan et al. (2010). Recently, an evidence-based analysis examining thyroid and aging reported that subclinical hyperthyroidism was associated with a higher incidence of cognitive impairment, but there was no evidence to support use of antithyroid drugs for dementia (Aggarwal and Ravzi, 2013).

Nervous system tissues contain a relatively high ratio of $\mathrm{T}_{3} / \mathrm{T}_{4}$ compared to circulation or non-nervous tissues (Nunez et al., 2008). DIO and type 3 deiodinase are both expressed in the nervous systems and control TH activity. Eighty percent of $\mathrm{T}_{3}$ in the brain is generated from $\mathrm{T}_{4}$ by $\mathrm{DIO}_{2}$, which is expressed in glial cells. Thus, $\mathrm{DIO}_{2}$ activity may affect the neurophysiology of neurons. $\mathrm{DIO}_{2}$ is considered an important enzyme in the maintenance of intracellular $\mathrm{T}_{3}$ levels in the central nervous system. The expression of $\mathrm{DIO}_{2}$ in the brain and pituitary cell may increase during hypothyroidism to maintain $\mathrm{T}_{3}$ level and cell function (Croteau et al., 1996). The $\mathrm{DIO}_{2}$ gene is located on human chromosome 14q24.2-24.3 and includes 2 exons and 1 intron. The cDNA contains 918 nucleotides of the open reading frame that encodes a 30-kDa protein. Two commonly occurring polymorphisms have been described in the human $\mathrm{DIO}_{2}$ gene and influence TH action. For example, the Thr92Ala polymorphism can reduce $\mathrm{DIO}_{2}$ activity and $\mathrm{T}_{3}$ concentration. In contrast, the ORFa-Gly3Asp variant can enhance the transcriptional activity of $\mathrm{DIO}_{2}$ and $\mathrm{T}_{3}$ concentration (Butler et al., 2010; Peltsverger et al., 2012).

The Thr92Ala polymorphism has also been linked to an increased risk of schizophrenia (Colak et al., 2013) and mental retardation (Guo et al., 2004). $\mathrm{DIO}_{2}$ gene polymorphisms may be associated with intelligence development, but few studies have identified a relationship between $\mathrm{DIO}_{2}$ gene polymorphisms and MCI or AD. Our study indicated that there were no statistical differences in genotype or allele frequencies in the $\mathrm{DIO}_{2}$ gene (Thr92Ala or ORFa-Gly3Asp) and the MCI group compared with control subjects in a Uygur population 
$(\mathrm{P}>0.05)$. However, we observed that the Ala allele frequency in the MCI group for males (48.6\%) was higher than that in the control group (38.7\%), although the difference was not significant $(\mathrm{P}=0.08)$. Male carriers of the Ala allele may have an increased incidence of $\mathrm{MCI}$, but the difference is not significant. Further studies examining the correlation between different genotypes of Thr92Ala and TH found that the level of TH for Ala/Ala carriers was much lower than that of Thr/Thr and Thr/Ala carriers $(\mathrm{P}<0.05)$, consistent with the results of Canani et al. (2005). Male carriers of the Ala allele accompanied by decreased TH showed an increased risk of MCI. No association was found between women carrying the Thr92Ala mutation and the incidence of MCI.

ORFa-Gly3Asp genotype and allele frequencies were significantly different between MCI patients and the control group according to gender $(\mathrm{P}<0.05)$. Male carriers of the Asp allele were less common among MCI patients than among controls. The risk of MCI was decreased in male carriers of the Asp allele $(\mathrm{OR}=0.471, \mathrm{P}<0.05)$. Examination of the relationship between different genotypes of ORFa-Gly3Asp and TH revealed that the serum level of $\mathrm{T}_{3}$ in male carriers of the Asp allele was higher than that of Gly carriers, which was consistent with the results of Coppotelli et al. (2006). Thus, the Gly3Asp mutation in males may increase the serum level of $\mathrm{T}_{3}$, decrease the incidence of MCI, and act as a protective factor. In contrast, female carriers of the Asp allele were more frequent among MCI patients $(\mathrm{OR}=2.842, \mathrm{P}<0.05)$. However, the serum levels of $\mathrm{T}_{3}$ with Gly/Gly, Gly/Asp, and Asp/Asp genotypes showed no difference in women $(\mathrm{P}>0.05)$. Thus, the effect of increased $\mathrm{T}_{3}$ concentration on the ORFa-Gly3Asp mutation was limited. This may be because hormone levels can influence the cognitive function of postmenopausal women (Ryan et al., 2012), acting as confounding factors. The number of women enrolled in this study was low, and the frequency of the Gly3Asp mutation in the Hapmap database was very low in Asia. Being female is a risk factor for MCI. Therefore, a single gene mutation may not be the main factor altering TH level. However, the results are biased, and whether an association exists between the Gly3Asp mutation in females and MCI remains unknown. Thus, a common mutation in the $\mathrm{DIO}_{2}$ gene may play a role in the incidence of male MCI.

In summary, we examined the relationship between common single-nucleotide polymorphisms in the $\mathrm{DIO}_{2}$ and MCI through epigenetic analysis. The sample size was small and we did not conduct the analysis based on ethnicity. Additional studies examining differences in microRNA will increase the understanding of changes in RNA and protein levels and their regulation as well as the signaling pathways of nerve cells.

\section{ACKNOWLEDGMENTS}

Research supported by the National Natural Science Foundation of China (\#30960402) and the Xinjiang Natural Science Foundation of China (\#2013211A095).

\section{REFERENCES}

Aggarwal N and Razvi S (2013). Thyroid and aging or the aging thyroid? An evidence-based analysis of the literature. $J$. Thyroid Res. 2013: 481287.

Bai J, Gao Y and Zhao GP (2011). Features of cognitive function impairment in old patients with subclinical hypothyroidism. J. Clin. Neurol. 24: 68-70.

Butler PW, Smith SM, Linderman JD, Brychta RJ, et al. (2010). The Thr92Ala 5' type 2 deiodinase gene polymorphism is associated with a delayed triiodothyronine secretion in response to the thyrotropin-releasing hormone-stimulation 
test: a pharmacogenomic study. Thyroid 20: 1407-1412.

Canani LH, Capp C, Dora JM, Meyer EL, et al. (2005). The type 2 deiodinase A/G (Thr92Ala) polymorphism is associated with decreased enzyme velocity and increased insulin resistance in patients with type 2 diabetes mellitus. J. Clin. Endocrinol. Metab. 90: 3472-3478.

Colak A, Akan G, Oncu F Yanbay H, et al. (2013). A association study of the dio2 gene as a susceptibility candidate for schizophrenia in the turkish population: a case-control study. European Psychiatry 28: 1.

Coppotelli G, Summers A, Chidakel A, Ross JM, et al. (2006). Functional characterization of the 258 A/G (D2-ORFaGly3Asp) human type-2 deiodinase polymorphism: a naturally occurring variant increases the enzymatic activity by removing a putative repressor site in the 5'UTR of the gene. Thyroid 16: 625-632.

Croteau W, Davey JC, Galton VA and St Germain DL (1996). Cloning of the mammalian type II iodothyronine deiodinase. A selenoprotein differentially excessed and regulated in human and rat brain and other tissues. J. Clin. Invest. 98 : 405-417.

Guo TW, Zhang FC, Yang MS, Gao XS, et al. (2004). Positive association of the DIO2 (deiodinase type 2) gene with mental retardation in the iodine-deficient areas of China. J. Med. Genet. 41: 585-590.

Jahagirdar V and McNay EC (2012). Thyroid hormone's role in regulating brain glucose metabolism and potentially modulating hippocampal cognitive processes. Metab. Brain Dis. 27: 101-111.

Lazarus JH (2012). Thyroid hormones and cognitive function. Expert Rev. Endocrinol. Metab. 7: 365-367.

Mafrica F and Fodale V (2008). Thyroid function, Alzheimer's disease and postoperative cognitive dysfunction: a tale of dangerous liaisons? J. Alzheimers Dis. 14: 95-105.

Nunez J, Celi FS, Ng L and Forrest D (2008). Multigenic control of thyroid hormone functions in the nervous system. Mol. Cell. Endocrinol. 287: 1-12.

O’Barr SA, Oh JS, Ma C, Brent GA, et al. (2006). Thyroid hormone regulates endogenous amyloid-beta precursor protein gene expression and processing in both in vitro and in vivo models. Thyroid 16: 1207-1213.

Peltsverger MY, Butler PW, Alberobello AT, Smith S, et al. (2012). The -258 A/G (SNP rs12885300) polymorphism of the human type-2 deiodinase gene is associated with a shift in the pattern of secretion of thyroid hormones following a TRH-induced acute rise in TSH. Eur. J. Endocrinol. 166: 839-845.

Prinz PN, Scanlan JM, Vitaliano PP, Moe KE, et al. (1999). Thyroid hormones: Postive relationship with cognition in healthy, euthyroid older men. J. Gerontol. A Biol. Sci. Med. Sci. 54: 111-116.

Quinlan P, Nordlund A, Lind K, Gustafson D, et al. (2010). Thyroid hormones are associated with poor cognition in mild cognitive impairment. Dement. Geriatr. Cogn. Disord. 30: 205-211.

Ryan J, Stanczyk FZ, Dennerstein L, Mack WJ, et al. (2012). Hormone levels and cognitive function in postmenopausal midlife women. Neurobiol. Aging 33: 1138-1147.

Stern RA, Davis JD, Rogers BL, Smith KE, et al. (2004). Preliminary study of the relationship between thyroid status and cognitive and neuropsychiatric functioning in euthyroid patients with Alzheimer dementia. Cog. Behav. Neurol. 17: 219-223.

Wang BY, Yang H, Zhong Y, Miao Y, et al. (2011). Clinical study on levels of blood fat, Folic acid, vitamin $\mathrm{B}_{12}$ and thyroid hormone in elderly patients with mild cognitive impairment. Modern J. Integrated Trad. Chin. West Med. 20: 4464-4466.

Zhou XH, Liang J, Dong LM, Zhang ZY, et al. (2012). Study of thyroid hormone level in mild cognitive impairment dysfunction patients in Xinjiang Uygur and Han nationalities. Chin. J. Lab. Med. 35: 921-925. 